\title{
CLINICAL SPECTRUM OF VENTRICULAR SEPTAL DEFECT IN CHILDREN IN A TERTIARY CARE HOSPITAL
}

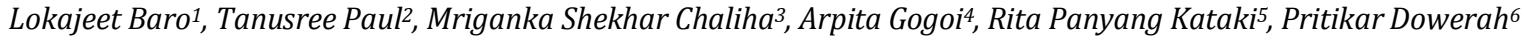

${ }_{1}^{1}$ Associate Professor, Department of Paediatrics, Assam Medical College \& Hospital, Dibrugarh, Assam.

${ }^{2}$ Registrar, Department of Paediatrics, Gauhati Medical College \& Hospital, Guwahati, Assam.

${ }^{3}$ Associate Professor, Department of Cardiology, Assam Medical College \& Hospital, Dibrugarh.

${ }^{4}$ Assistant Professor, Department of Paediatrics, Assam Medical College \& Hospital, Dibrugarh, Assam.

${ }^{5}$ Assistant Professor, Department of Paediatrics, Assam Medical College \& Hospital, Dibrugarh, Assam.

${ }^{6}$ Professor and HOD, Department of Paediatrics, Assam Medical College \& Hospital, Dibrugarh, Assam.

\section{ABSTRACT}

\section{BACKGROUND}

Ventricular Septal Defect (VSD) is the most common congenital heart disease in children. Our study was done with the aim to analyse the clinical profile and size and type of VSD in Paediatric patients admitted in a tertiary care hospital in Assam.

\section{METHOD}

This is a prospective cross-sectional study of 2 years' duration conducted in the Department of Paediatrics, Assam Medical College, Dibrugarh. Children aged 1 month to 12 years with a clinical diagnosis of VSD were evaluated by echocardiography to confirm the diagnosis. Only isolated VSD cases were enrolled in the study. Data was entered and analysed by SPSS version 16.

\section{RESULT}

Among the total of 70 cases, $47.1 \%$ were female and $52.9 \%$ were male; $54.3 \%$ cases presented in infancy and 46 patients (65.7\%) had their first symptom before one year. Perimembranous was the commonest (74.3\%) followed by muscular (22.9\%) and doubly committed subarterial (2.9\%) VSD. Common symptoms were cough (68.6\%), fever (68.6\%), breathlessness (52.9\%), feeding problem (45.7\%), failure to thrive $(45.7 \%)$ and fatigue (40\%). Pansystolic murmur (100\%), tachypnoea (62.9\%), tachycardia (62.9\%), crepitations (57.1\%), subcostal retraction (45.7\%), hepatomegaly (34.3\%) and wheeze (20\%) were the frequent clinical findings. Complications associated were pneumonia (57.1\%), malnutrition (51.4\%), congestive cardiac failure (CCF) (34.3\%) and pulmonary hypertension (17.1\%).

\section{CONCLUSION}

Perimembranous was the commonest type of VSD. Small VSD presented with mild symptoms or were asymptomatic. Moderate and large VSD presented with severe symptoms and complications. Clinical examination and diagnostic modalities like chest X-ray, ECG and echocardiography is helpful in diagnosing VSD. Early diagnosis and management will help in preventing the associated complications, thereby reducing the mortality and morbidity in these children.

\section{KEYWORDS}

Ventricular Septal Defect, Congestive Cardiac Failure, Echocardiography.

HOW TO CITE THIS ARTICLE: Baro L, Paul T, Chaliha MS, et al. Clinical spectrum of ventricular septal defect in children in a tertiary care hospital. J. Evolution Med. Dent. Sci. 2016;5(52):3412-3415, DOI: 10.14260/jemds/2016/788

\section{INTRODUCTION}

Ventricular Septal Defect (VSD) is the most common cardiac malformation of the heart accounting for $25 \%$ of Congenital Heart Disease (CHD). ${ }^{1}$ Isolated VSD affects approximately 26/1000 live births.2,3 Ventricular Septal Defect (VSD) is a developmental defect of the interventricular septum resulting from a deficiency of growth or a failure of alignment or fusion of component parts of ventricular septum. ${ }^{4}$ Soto et al ${ }^{5}$ classified VSD into 3 types: perimembranous, muscular and Doubly Committed Subarterial (DCSA) types depending upon the location.

Financial or Other, Competing Interest: None.

Submission 12-05-2016, Peer Review 07-06-2016,

Acceptance 11-06-2016, Published 30-06-2016.

Corresponding Author:

Dr. Lokajeet Baro,

Associate Professor,

Department of Paediatrics,

Assam Medical College and Hospital,

Dibrugarh-786002, Assam.

E-mail: lokajeet.b@rediffmail.com

DOI: 10.14260/jemds/2016/788
Perimembranous defect is the commonest accounting for about $70-80 \%$ of cases. ${ }^{6,7}$ The natural course of VSD depends to a large degree on the size of the defect. Small VSD with trivial left to right shunt and normal pulmonary arterial pressure are asymptomatic and is usually found during routine physical examination. Large VSD with excessive pulmonary blood flow and pulmonary hypertension are responsible for dyspnoea, feeding difficulties, poor growth, profuse perspiration and cardiac failure in early infancy. ${ }^{1}$

Although a few studies have been conducted in India, CHD especially VSD in children have not been studied thoroughly in this part of northeast India. Previous studies also lack information regarding clinical profile and size and type of lesion. Our study aims to present a single centre experience of VSD in children at Assam Medical College and Hospital, which is a tertiary care centre catering to the seven upper Assam districts and adjoining state of Arunachal Pradesh. The results of this study will be useful for initiating early diagnosis and proper management, which will result in decreasing the mortality and morbidity. 


\section{MATERIALS AND METHODS}

The study was conducted in the Department of Paediatrics, Assam Medical College Hospital in Dibrugarh, Assam, during June 2013 to May 2015. All children aged 1 month to 12 years attending Paediatric OPD/IPD with clinical diagnosis of VSD were evaluated by echocardiography to confirm the diagnosis. Only cases of isolated VSD (Absence of other cardiac anomaly) were included in the study. Size and location of the defect were identified by two dimensional transthoracic, colour Doppler echocardiography in the Department of Cardiology. Patients were grouped into three different classes: small, moderate and large based on size of aortic root. Lesions that approximate the size of the aorta are considered large; lesion one-third to twothirds of the diameter of aorta are moderate; and lesions less than one-third the aortic root diameter are considered small. 8 VSD were classified as perimembranous, muscular, Doubly Committed Subarterial (DCSA), and inlet VSD according to Soto's classification. ${ }^{5}$

A thorough history, anthropometric measurement and along with chest X-ray and ECG were done in all the cases. Anthropometric procedures were performed according to standard WHO procedure.

Data was entered and analysed by using SPSS- 16 .

\section{RESULT AND OBSERVATION}

In our study, a total of 70 patients were included during the period of two years. Out of the total patients, 33 (47.1\%) were female and 37 (52.9\%) were male. Male:female ratio was 1.12:1.

Amongst the 70 patients, 46 patients $(65.7 \%)$ had their first symptom before the age of one year and only $9(12.9 \%)$ had their first symptom after 5 years of age. Similarly, 38 $(54.3 \%)$ patients were below one year of age at presentation (Table 1).

Echocardiography done in the study subjects found 31 cases (44.3\%) had small VSD, 21 cases (30\%) had moderate VSD, while 18 cases (25.7\%) had large VSD (Fig. 1).

Among the VSD cases, $74.3 \%$ (52) children had perimembranous, $22.9 \%$ (16) had muscular and only $2.9 \%$ (2) had DCSA type of VSD. There was no case of inlet type of VSD (Fig. 2).

Regarding the clinical presentation, $68.6 \%$ of patients presented with cough and fever. Other presentation includes breathlessness (52.9\%), feeding problem (45.7\%), failure to thrive $(45.7 \%)$ and fatigue $(40 \%)$. Out of the thirty one patients of small VSD cases in the study, 10 (32.3\%) patients were asymptomatic. The major signs in order of frequency were pansystolic murmur (100\%), tachypnoea (62.9\%), tachycardia (62.9\%), crepitations (57.1\%), subcostal retraction ( $45.7 \%)$, hepatomegaly (34.3\%), and wheeze (20\%) (Table 2).

On enquiring about the past history, 36 cases (51.4\%) had recurrent pneumonia, 32 cases (45.7\%) had feeding problem, 28 cases $(40 \%)$ had fatigue and these were found mostly in moderate-to-large VSD.

Among the complications that were frequently associated were pneumonia $(40,57.1 \%)$ followed by malnutrition $(36$, 51.4\%) and CCF $(24,34.3 \%)$. Pulmonary hypertension accounted for $(12,17.1 \%)$ of the cases (Table 3$)$. Amongst the 36 cases of malnutrition, 24 patients $(34.3 \%)$ had severe malnutrition and 12 patients had moderate malnutrition
(17.1\%). Complications were mostly observed in moderate-tolarge VSD.

Among the other investigations done, chest X-ray finding of cardiomegaly and plethora were seen in $58.6 \%$ (41) of cases. ECG was normal in 32 cases (45.7\%), 28 cases (40\%) had left ventricular hypertrophy, 6 cases $(8.6 \%)$ had right ventricular hypertrophy and 4 cases $(5.7 \%)$ had biventricular hypertrophy.

\begin{tabular}{|c|c|c|}
\hline Age Group & $\begin{array}{c}\text { At } \\
\text { Presentation }\end{array}$ & $\begin{array}{c}\text { At First } \\
\text { Symptom }\end{array}$ \\
\hline $\begin{array}{c}\text { 1 month to }<1 \\
\text { year }\end{array}$ & $38(54.3 \%)$ & $46(65.7 \%)$ \\
\hline 1 year to <5 years & $22(31.4 \%)$ & $15(21.4 \%)$ \\
\hline $\begin{array}{c}\text { 5 years to } 12 \\
\text { years }\end{array}$ & $10(14.3 \%)$ & $9(12.9 \%)$ \\
\hline Total & $\mathbf{7 0}(\mathbf{1 0 0} \%)$ & $\mathbf{7 0}(\mathbf{1 0 0} \%)$ \\
\hline \multicolumn{2}{|c|}{ Table 1: Age of Patient $(\boldsymbol{n}=\mathbf{7 0})$} \\
\hline
\end{tabular}

\begin{tabular}{|c|c|c|}
\hline Symptoms & $\mathrm{N}=\mathbf{7 0}$ & Percentage \\
\hline Cough & 48 & 68.6 \\
\hline Fever & 48 & 68.6 \\
\hline Breathlessness & 37 & 52.9 \\
\hline Feeding problem & 32 & 45.7 \\
\hline Failure to thrive & 32 & 45.7 \\
\hline Fatigue & 28 & 40 \\
\hline Asymptomatic & 10 & 14.3 \\
\hline Pansystolic murmur & 70 & 100 \\
\hline Tachypnoea & 44 & 62.9 \\
\hline Tachycardia & 44 & 62.9 \\
\hline Crepitations & 40 & 57.1 \\
\hline Subcostal Retraction & 32 & 45.7 \\
\hline Hepatomegaly & 24 & 34.3 \\
\hline Wheeze & 22 & 31.4 \\
\hline \multicolumn{3}{|c|}{ Table 2: Signs and Symptoms $(n=70)$} \\
\hline
\end{tabular}

\begin{tabular}{|c|c|c|c|c|}
\hline Complications & $\begin{array}{c}\text { Small } \\
\text { VSD } \\
(n=31)\end{array}$ & $\begin{array}{c}\text { Moderate } \\
\text { VSD } \\
(\mathbf{n}=\mathbf{2 1})\end{array}$ & $\begin{array}{c}\text { Large } \\
\text { VSD } \\
(n=18)\end{array}$ & $\begin{array}{c}\text { Total } \\
(\mathrm{N}=70)\end{array}$ \\
\hline Pneumonia & $\begin{array}{c}18 \\
(58.1 \%)\end{array}$ & $\begin{array}{c}12 \\
(57.1 \%)\end{array}$ & $\begin{array}{c}10 \\
(55.6 \%)\end{array}$ & $\begin{array}{c}40 \\
(57.1 \%)\end{array}$ \\
\hline $\mathrm{CCF}$ & $2(6.5 \%)$ & $\begin{array}{c}8 \\
(38.1 \%) \\
\end{array}$ & $\begin{array}{c}14 \\
(77.8 \%) \\
\end{array}$ & $\begin{array}{c}24 \\
(34.3 \% \\
\end{array}$ \\
\hline PHTN & Nil & $\begin{array}{c}4 \\
(19 \%)\end{array}$ & $\begin{array}{c}8 \\
(44.4 \%)\end{array}$ & $\begin{array}{c}12 \\
(17.1 \%)\end{array}$ \\
\hline Malnutrition & $\begin{array}{c}7 \\
(22.6 \%)\end{array}$ & $\begin{array}{c}13 \\
(61.9 \%) \\
\end{array}$ & $\begin{array}{c}16 \\
(88.9 \%) \\
\end{array}$ & $\begin{array}{c}36 \\
(51.4 \%)\end{array}$ \\
\hline
\end{tabular}

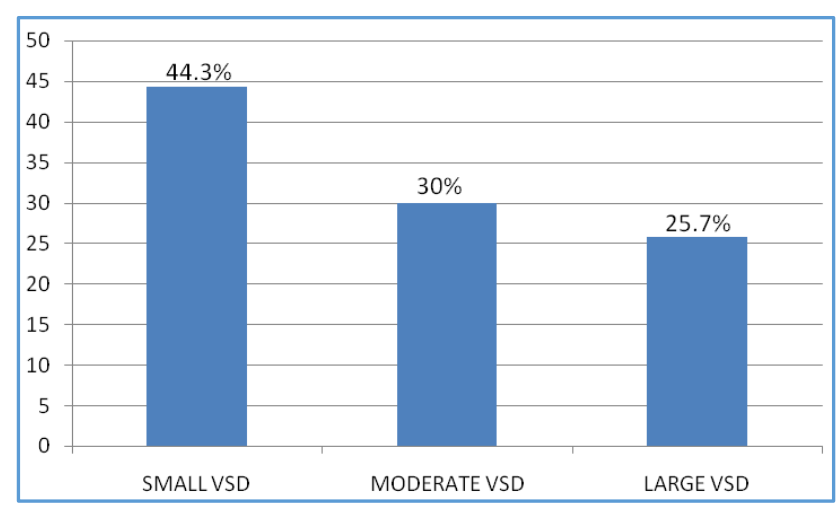

Fig. 1: Size of VSD (no=70) 


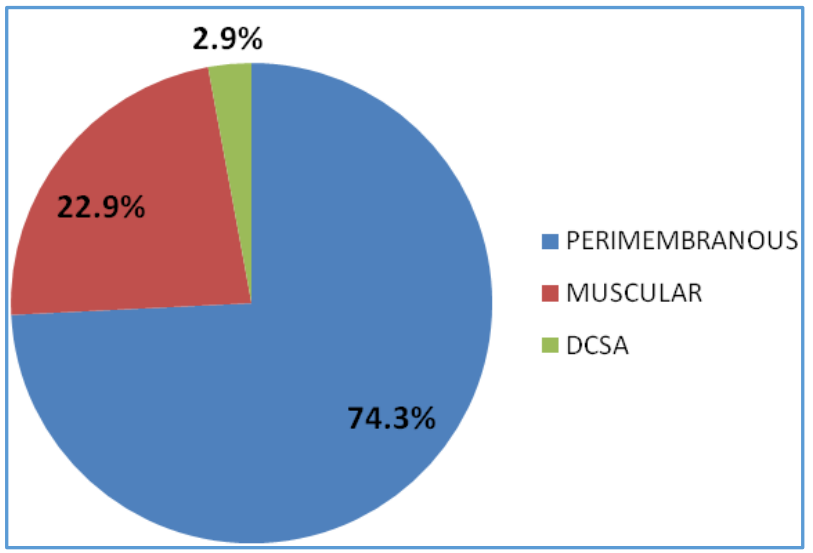

Fig. 2: Anatomical Type of VSD (no=70)

\section{DISCUSSION}

VSD is the commonest acyanotic congenital heart disease in children. Knowing the clinical profile of VSD will help in early diagnosis and treatment leading to development of fewer complications. Our study is confined to the patients who have attended Department of Paediatric, Assam Medical College and Hospital, which is a tertiary care hospital catering to the people of seven upper Assam districts and adjoining state of Arunachal Pradesh.

In our study, majority of the cases (54.3\%) presented in infancy. Among the study subjects, $65.7 \%$ had their 1 st symptom below the age of 1 year. This is comparable with the studies done in Pakistan. ${ }^{9}$

Our study shows a male preponderance with a male:female ratio of 1.12:1. Kazmi et al ${ }^{10}$ and Chaudhry et al ${ }^{11}$ also reported a predominance in males.

In our study size of VSD was small, moderate and large in $44.3 \%, 30 \%$ and $25.7 \%$ respectively; similar observation was found in other studies.12,13 Among the anatomical types, perimembranous was the commonest type (74.3\%) followed by muscular type $(22.9 \%)$ and the least frequent were DCSA type (2.9\%). These results were in keeping with what is found in Western literature. ${ }^{8}$ and also in studies conducted in Pakistan. ${ }^{10,11}$

Regarding clinical presentation, the most common symptoms were cough, fever, breathlessness, feeding problem, failure to thrive and fatigue. These findings were consistent with the studies done by other workers. ${ }^{14,15}$ In our study about $32.3 \%$ of small VSD cases were asymptomatic. These cases were admitted in hospital for other disease condition and incidentally diagnosed during routine examination. Recurrent chest infection has been found to be a frequent complication of VSD in several studies. ${ }^{16,17}$ Among the study group, about $51.4 \%$ had past history of recurrent pneumonia.

of the clinical signs, pansystolic murmur, tachypnoea, tachycardia, crepitations, subcostal retraction, hepatomegaly and wheeze were the most frequent findings. The same picture has been reported in studies done in other developing countries. ${ }^{14,15}$

Regarding complications, CCF was present in $34.3 \%$ of the patients. CCF was seen mostly in cases with moderate-to-large VSD. This finding correlate with study done by other worker. ${ }^{14}$ in our study. It was seen that growth was affected by the size of VSD. Malnutrition was more common in large VSD (88.9\%) and moderate VSD (61.9\%) as compared to small VSD (22.6\%). Severe malnutrition was present in $34.3 \%$ and moderate malnutrition was present in $17.1 \%$ cases. Quasy et al ${ }^{18}$ in his study found the same pattern. Pulmonary hypertension was seen in $30.8 \%$ of cases of moderate-to-large VSD. Small VSD cases were not associated with pulmonary hypertension. Choudhry et al11 in his study found severe pulmonary hypertension to be the most common complication associated with large VSD.

On chest X-ray, $58.6 \%$ VSD cases had cardiomegaly and plethora. Harshangi et $\mathrm{al}^{15}$ in their study found that all the cases of isolated VSD had cardiomegaly on CXR. Plethora was present in $93.3 \%$ cases. In another study by Hussain et $\mathrm{al}^{9}$, cardiomegaly was found in $89.8 \%$ of patients. This could be because of the fact that their study included only VSD patients with CCF. Moreover, majority of cases (44.3\%) included in our study were small VSD.

Study done by Hussain et al $^{9}$ showed normal ECG in $28 \%$ cases with important ECG abnormalities being left axis deviation (65.3\%). Present study was in concordance with this study. On analysis of the ECG $40 \%$ had left ventricular hypertrophy, while $8.6 \%$ had right ventricular hypertrophy and $5.7 \%$ had biventricular hypertrophy. Normal ECG was seen in $45.7 \%$ cases.

\section{CONCLUSION}

Most of the patient of VSD presented in infancy. Perimembranous was the commonest type of VSD. The clinical presentation of VSD vary from asymptomatic to severe symptoms, depending on the size of VSD. Patients of small VSD presented with mild symptoms or were asymptomatic. Moderate and large VSD mainly presented with severe symptoms. Complications like CCF, pulmonary hypertension, malnutrition and failure to thrive were mostly present in patient with moderate-to-large VSD. A detailed history, cardiovascular and other systemic examination and diagnostic modalities like chest X-ray, ECG and echocardiography is helpful in diagnosing VSD. Early diagnosis and management will help in preventing the associated complications, thereby reducing the mortality and morbidity in these children.

\section{REFERENCES}

1. Bernstein D. Acyanotic congenital heart disease: The leftto-right shunt lesions. In: Behrhman RE, Kliegman RM, Jenson HB, et al. (eds). Nelson Textbook of Paediatrics. 17th ed. W.B. Saunders Co, 2004:1888-90.

2. Samanek M, Voriskova M. Congenital heart disease among 815, 569 children born between 1980 and 1990 and their 15-year survival: a prospective bohemia survival study. Paediatr Cardiol 1999;20(6):411-7.

3. Tynan M, Anderson RH. Ventricular septal defect. In: Anderson RH, Baker EJ, McCartney FJ, (eds.) Paediatric Cardiology. London: Churchill Livingstone, 2002:9831014.

4. Praagh R, Geva T, Kreutzer J. Ventricular septal defects: how shall we describe, name and classify them? J Am Coll Cardiol 1989;14(5):1298-9.

5. Soto B, Becker AE, Moulaert AJ, et al. Classification of ventricular septal defects. Br Heart J 1980;43(3):332-43.

6. Wickramasinghe $P$, Lamabadusuriya SP, Nerenthiran S. Prospective study of congenital heart disease in children. Ceylon Med J 2001;46(3):96-8.

7. Perloff JK. Clinical recognition of congenital heart disease. Philadelphia, PA. Saunders, 2003. 
8. McDaniel NL, Gutgesell HP. Ventricular septal defect. In: Allen HD, Driscoll DJ, Sheddy RE, et al. (eds.) Moss and Adams' Heart Disease in Infants, Children and Adolescent. $7^{\text {th }}$ ed. Philadelphia: Lippincott Williams \& Willkins, 2008:667-82.

9. Hussain M, Hussain S, Krishin J, et al. Presentation of congestive cardiac failure in children with ventricular septal defect. J Ayub Med Coll Abbottabad 2010;22(4):135-8.

10. Kazmi U, Sadiq M, Hyder SN. Pattern of ventricular septal defects and associated complications. J Coll Physicians Surg Pak 2009;19(6):342-5.

11. Chaudhry TA, Younas M, Baig A. Ventricular septal defect and associated complications. J Pak Med Assoc 2011;61(10):1001-4.

12. Layangool T, Kirawittaya T, Sangtawesin C, et al. Natural aortic valve complications of ventricular septal defect: a prospective cohort study. J Med Assoc Thai 2008;91(Suppl 3):53-9.
13. Mohammad N, Shaikh S, Memon S, et al. Spectrum of heart disease in children under 5 years of age at Liaquat University Hospital, Hyderabad, Pakistan. Indian Heart J 2014;66(1):145-9.

14. Sharmin L, Haque M, Bari M, et al. Pattern and clinical profile of congenital heart disease in a teaching hospital. TAJ: J of Teachers Assoc 2008;21(1):58-62.

15. Harshanghi S, Itagi L, Patil V, et al. Clinical study of congenital heart disease in infants in tertiary care hospital. Journal of Pharmaceutical and Scientific Innovation 2013;2(1):15-8.

16. Ramachandran U, Alurkar V, Thaplia A. Pattern of cardiac diseases in children in Pokhara, Nepal. Kathmandu Univ Med J 2006;4(2):222-7.

17. Memon Y, Majeed R, Memon F. Pattern of congenital heart disease at Liaquat university hospital Hyderabad. Pak Heart J 2007;40(1-2):9-13.

18. Qusay A, Al-Rahim, Al-Hamash S, et al. Effect of ventricular septal defect on the growth pattern of children. The Iraqi Postgraduate Medical Journal 2006;5(1):8-13. 